\title{
Review
}

\section{Patient-Centered Methods for Designing and Developing Health Information Communication Technologies: A Systematic Review}

\author{
Katharine M. Mitchell, MA, ${ }^{1}$ Bree E. Holtz, PhD, ${ }^{1}$ \\ and Alexis McCarroll, $B A^{2}$
}

${ }^{1}$ Department of Advertising and Public Relations, ${ }^{2}$ Department of Media and Information, Michigan State University, East Lansing, Michigan.

\begin{abstract}
Background: Chronic disease management and maintaining healthy behaviors to prevent disease are important lifelong considerations. Adherence to prescribed management and behaviors often falls short of physician recommendations, which can result in negative health outcomes. Information communication technologies (ICTs) offer an approach to combat this issue. However, uptake and sustainability of ICTs have mixed results. One reason could be that technologies are often created without an understanding of the complexities of patient needs. Therefore, the intent of this study is to explore the current landscape of patient-centered design and development of health ICTs through a systematic review.

Materials and Methods: Systematic literature searches were conducted in the databases EBSCO, PubMed, and Web of Science between October 2016 and February 2017. Each paper was critically evaluated for each data extraction classification, and was categorized based on the chronic disease or health focus, method of patient-centered design, resulting themes, and use of theory.

Results: The study search resulted in 3,748 articles total. After duplicates and articles not meeting criteria were removed, 57 articles were selected for assessment. Four main themes emerged: participant experience, technological requirements, behavioral and knowledge components, and social components.

Conclusions: Adhering to chronic disease management and healthy behaviors are both crucial to attain positive health outcomes. ICTs can play an interesting role in aiding disease management and healthy behavior promotion, but involving endusers and applying a theoretical foundation in the design and development of these technologies should be considered.
\end{abstract}

Keywords: e-health, m-health, technology, telemedicine, telecommunications

\section{Introduction}

$1 \mathrm{n}$ estimated 5.5 million individuals in the United States live with one or more chronic disease(s), which often have long-lasting impacts on individuals throughout their life span. ${ }^{1,2}$ In addition to chronic disease management, healthy behaviors to prevent and manage disease are important lifelong considerations for most adults. ${ }^{3}$ Adherence to prescribed disease management and healthy behaviors tends to fall short of physician recommendations. ${ }^{4}$ Possible explanations include a lack of knowledge, low efficacy, and cost of management. ${ }^{5}$ Increasing knowledge and efficacy are important components in improving health outcomes. ${ }^{6,7}$ Therefore, creating an enjoyable and cost-effective way to increase knowledge, efficacy, and ultimately improve adherence is imperative to better health outcomes. ${ }^{8,9}$ One cost-effective method to help combat poor outcomes in these dimensions is through the use of information communication technologies (ICTs). ${ }^{10}$

ICTs are at the forefront of health care today and are nearly ubiquitous in the United States, with 77\% of adults having a smartphone. ${ }^{11,12}$ Health care providers often recommend ICTs for their patients' chronic disease management. ${ }^{13,14}$ Studies show that using technologies can positively impact treatment adherence rates. ${ }^{15,16}$ However, uptake and long-term sustainability of use have mixed results. ${ }^{17,18}$ One reason could be that these technologies are often created by companies that may not understand the complexities of health or patient needs. ${ }^{17,19,20}$

Incorporating end-users throughout the design and development process is not very common, but has great potential for creating effective ICTs. ${ }^{21}$ Evaluating usability and satisfaction of already developed health ICTs is more common, and results are generally positive. ${ }^{22-24}$ However, involving patients earlier in the process and using their feedback in design and development can ensure functionality, usability, engagement, and ultimately increase the potential for impacting health outcomes. ${ }^{21,25}$

In addition to the patient perspective, theory may play an important role in the development of effective ICTs. Theory is frequently incorporated into study design because it helps provide explanations rather than solely predictions on the 


\section{PATIENT-CENTERED ICTS}

effectiveness of interventions. ${ }^{26}$ In the case of ICTs, the impact of incorporating theory into the design and development remains in question. However, integrating theory into the design and development of ICTs should have the potential to offer explanations on outcomes in a similar manner to theory use in study design. Therefore, authors also sought to uncover the prevalence of theory use for design and development of health-related ICTs to begin understanding the extent to which theory can be beneficial in this context.

\section{Methods}

For the purpose of this review, the authors focused particularly on patient-centered, formative research methods used to develop health ICTs for patients. Consequently, the majority of the studies meeting criteria did not provide quantitative health outcomes. Therefore, a meta-analysis was not conducted and instead, descriptive themes were generated to explore the current landscape of patient-centered design and development of health ICTs. ${ }^{27}$ This review was conducted and reported in accordance with the Preferred Reporting Items for Systematic Reviews and Meta-Analyses (PRISMA) statement (see checklist in Supplementary Appendix A).

The overall review questions are as follows: (1) What methods are being used to engage end-users in development of health-related ICTs (i.e., workshops, focus groups, etc.)? (2) How involved are end-users in the stages of development (i.e., one phase or multiple phases of development)? (3) What types of feedback are users providing (i.e., usability, health-related suggestions, communication-related suggestions)? (4) What theories are being used in design and development of ICTs? Supplementary Appendix B.I includes our research questions and provides definitions of categories.

\section{ELIGIBILITY CRITERIA}

For inclusion in this systematic review, studies had to (1) develop an ICT to test its impact on a chronic disease or healthy behavior of patients; (2) use patient-centered methods to develop the ICT; (3) have patients as end-users; and (4) be published in English. For further description of inclusion criteria, see Supplementary Appendix B.II.

We used a modified definition of ICTs for this review: the application of organized knowledge and skills in the form of personal technology devices that have been developed to solve a health problem and improve quality of lives. ${ }^{28,29}$ In addition, for this review, the health ICT must be developed for patients and be used to test its impact on a chronic disease or for the health of patients. Some examples of chronic disease include, but are not limited to, asthma, diabetes, and cancer. Finally, to be considered a patient-centered design method,
ICTs must be designed to incorporate features that matter to patients, ${ }^{30}$ and that directly involve end-users during the design and development stages to provide insight into questions of context and usefulness. ${ }^{31}$

\section{SEARCH STRATEGY}

Systematic literature searches were conducted in three databases, including EBSCO, PubMed, and Web of Science. Initial searches of these databases were conducted between October 2016 and February 2017. Search terms included combinations of key words using the Boolean operator AND (see Supplementary Appendix C for full list of terms). There was no exclusion parameter on the dates of publication. References of the articles found through the databases were hand searched to extract all relevant articles. Two coders (K.M.M., A.M.) independently reviewed the full list of articles to identify which met the specific inclusion criteria. To know the major variables assessed during data extraction, see Supplementary Appendix B.III.

\section{DATA EXTRACTION}

Data extracted included (1) article title, author, and publication year; (2) number of participants; (3) participants' age; (4) the chronic disease of focus; (5) a description of the technology; (6) a description of the patient-centered methods used to develop the technology; (7) the number of stages or iterations of design and development; and (8) use of theory. During the process of establishing reliability, the coding scheme was refined and explicated as necessary. Once reliability was established (Krippendorff's alpha $>0.8$ for each coded item), any discrepancies between the two reviewers were subject to multiple reviews, and then settled by consensus. ${ }^{32}$

\section{DATA ANALYSIS}

A meta-analysis was not performed because of the variety of chronic diseases, technologies, and themes assessed. Instead, researchers focused on generating descriptive themes to evaluate the articles. Systematic methods were used to summarize the findings, but the results of all of the studies reviewed were not statistically combined. ${ }^{33}$ Rather, each paper was critically evaluated for each data extraction classification, and categorized based on chronic disease or health focus, method of patient-centered design, resulting themes, and use of theory.

\section{Results}

\section{STUDY SELECTION}

The study search resulted in 3,748 articles, with 1,350 unique articles after duplicates were removed. An additional "by 


\section{MITCHELL ET AL.}

date" search of the databases was done to capture additional articles that were published between March 2017 and July 2017, which provided an additional 126 unique articles, resulting in 1,476 articles. Of those, 95 were full-text articles with abstracts describing patient-centered design of a technology for patients. The 95 studies were narrowed further during full article review as many did not meet criteria upon detailed examination. Once study selection was complete, 57 articles were selected for assessment. See Figure 1 for the study selection flow chart.

\section{STUDY CHARACTERISTICS}

Each study was evaluated using multiple criteria, including number and age of participants, chronic disease or healthy behavior of focus, description of technology, description of patient-centered methods, number of iterations, and theory use. Study characteristics are discussed below and can be found in Supplementary Appendix D.

Participants. The number of participants in the studies ranged from 3 to 59. Most studies (39\%) included $\leq 15$ participants. ${ }^{13,21,34-53}$ Fourteen studies had $>15$ but $<25$ participants, ${ }^{54-67}$ and 14 studies had between 26 and 59 participants. ${ }^{68-81}$ Three studies described the population but did not include the number of participants. ${ }^{82-85}$ Forty-four percent of participants from all studies combined identified as female, and participants' age ranged from 5 to 78 years $(\mathrm{M}=39.14, \mathrm{SD}=20.47)$. All participants had a chronic disease or the need to focus on a healthy behavior for which the technology was developed to impact. Each of the chronic diseases and healthy behaviors are included in the following section.

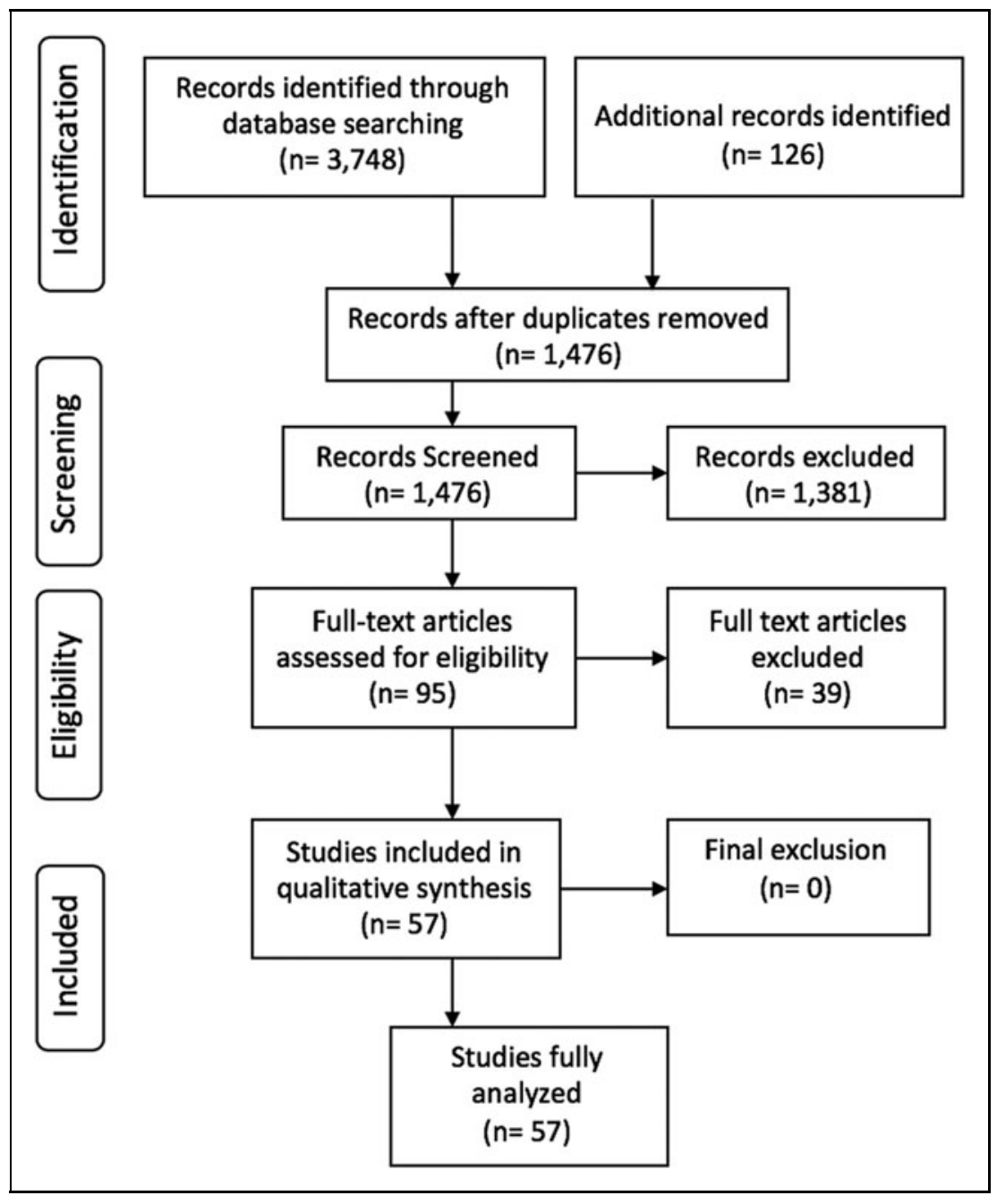

Fig. 1. Study selection flowchart.
Health technologies. Twenty-three chronic diseases or healthy behaviors were the focus of the designed technology in the assessed studies. Healthy behaviors included weight management, ${ }^{62,71,72}$ medication adherence and education, ${ }^{34,85}$ skin care, ${ }^{86}$ healthy behaviors for geriatric patients, ${ }^{64,73,80,83}$ postoperative health considerations, ${ }^{3,45,65}$ and sexual health. ${ }^{39,47,79,84}$ Chronic diseases included cancer, $^{35,50,53,54,59,69,74,82}$ gout, $^{36}$ lung disease, ${ }^{21,63}$ mental health, ${ }^{41,49,76,77}$ HIV, ${ }^{46,66}$ diabetes and kidney disease, ${ }^{13,42,43,51,55-57,61,68,70,78,81}$ arthritis, ${ }^{44}$ amblyopia, ${ }^{48}$ cardiovascular disease, ${ }^{52}$ lupus, ${ }^{58}$ autism, ${ }^{40}$ and chronic pain. ${ }^{37,60,67,75}$

The types of technologies that were created varied among the studies, and included a mobile app, ${ }^{13,21,34,35,37,42-44,46,57,58,60,63,65-72,74,77-80,82,84,86 ~}$ computer or tablet software, ${ }^{36,45,50,54,59,73,76,83,84}$ website or web application, ${ }^{43,44,48,52,53,67}$ personal health assistant, ${ }^{38,55,56,81}$ and a video game. $^{61,85} \mathrm{~A}$ handful of studies (11\%) simply indicated they were developing an ehealth tool but did not give further details about the technology..$^{40,47,49,51,62,64}$ The main purpose of the technology was also assessed. Self-management was the focus for many studies $(28 \%),{ }^{13,35,36,43-46,52,55,56,63,64,67,68,72,73}$ followed closely by education $(25 \%)^{34,39,42 \text {, }}$ $47,48,53,59,61,66,67,79,83,85,86$ and self-monitoring (23\%). ${ }^{21,37,51,57,60,62,65,67,70,71,78,80,81}$ Additional purposes included increasing communication, ${ }^{54,59,65,75}$ remote monitoring, ${ }^{40,50,74,82}$ 


\section{PATIENT-CENTERED ICTS}

social networking and social support, ${ }^{38,41,43,58,69,76,79,84}$ and prevention. $^{77}$

Patient-centered methods. Of the 57 studies reviewed, 15 (26\%) included focus groups, ${ }^{13,36,37,52,55,56,59,60,67,69-72,83,86}$ 13 (23\%) interviews, ${ }^{21,39,40,42,43,45,48,50,54,62,74,81,82} 11$ (19\%) workshops, ${ }^{41,44,46,49,53,58,61,63,65,80,85}$ and 2 (3\%) disseminated surveys. ${ }^{43,77}$ Ten (18\%) studies used a mixture of these methods, ${ }^{38,47,51,57,64,66,75,76,78,79}$ and 5 (9\%) studies were not explicit with their definition of patient-centered methods, but stated that end-users gave feedback on the design and development of the ICT. ${ }^{34,35,68,73,84}$

Among the 15 studies that included focus groups, the majority used semistructured methodology to gather feedback on health and technology. The groups varied in size and duration, with many studies not disclosing the number of participants or the duration. The interviews varied slightly among the 13 studies, and included both in-person and phone surveys. The interviews varied in time, and many studies did not note the length of the interview. The workshops were very different among the studies assessed. One study used a think-aloud protocol during the workshop, ${ }^{81}$ while other studies held group discussions to generate ideas for content ${ }^{46,58}$ and general design. ${ }^{63}$ Another study held design sessions to specifically help create the style of characters and the background. ${ }^{66}$

The majority of the studies had one to three phases of patient-centered contribution to the design and development of the technology. 13,21,35-37,39,40,43-47,49-51,53,55-57,59-61,63-65,

67,68,70,72-77,82,84,86 Some (23\%) studies had between four and six phases, ${ }^{34,38,41,42,48,52,54,62,66,69,71,79,80}$ and three studies had seven or more phases. ${ }^{58,83,85}$ Two studies included purely concept and design generation, followed by an evaluation, ${ }^{43,44}$ but all of the other studies were much more involved and included multiple phases that built on the feedback from the previous phase. For example, a mobile app for menopause included an initial round of workshops, focus group interviews, storyboard prototyping, individual interviews, and analysis. $^{79}$

\section{STUDY OUTCOMES}

Four main themes emerged from the assessed studies, including participant experience, technological requirements, behavioral and knowledge components, and social components. In addition, authors assessed if design and development was guided by theory.

Feedback theme 1: participant experience. Participant experience was a reoccurring theme within many of the studies (25\%). Participant experience fell into two main categories with associated subthemes: experiences with the particular disease or healthy behavior, and experiences with different types of technologies.

PARTICULAR DISEASE OR HEALTHY BEHAVIOR. This subtheme included topics such as (1) the impact of the disease, (2) any existing coping strategies, (3) current medical practices, (4) barriers to care, and (5) existing communication with caregivers or others.

The impact of the disease was assessed in two studies by gathering participant feedback on daily life with a particular disease. For example, the studies included qualitative interviews to explore different aspects of the individuals' daily life with type 1 diabetes. ${ }^{13,42}$ This information was used to establish a deeper understanding of users' needs. Existing coping strategies and current medical practices were subthemes that emerged from this review. ${ }^{37,42,43,55,69,75}$ Current planning processes for care visits were assessed in one study, with participant feedback helping to develop a tablet-based waiting room tool that enables complex patients to identify and set discussion topic priorities for their primary care visit. ${ }^{75}$ In addition, feedback on current disease screening and challenges with screening processes fell into this subtheme. With this information, an e-health tool was created. ${ }^{47}$ Three studies mentioned gathering feedback regarding current practices, including medication adherence and how they coped with management. $^{43,55,69}$ This information helped develop technologies with a goal to positively impact current practices and increase adherence and coping. Barriers to care was another subtheme mentioned in many of the studies. ${ }^{34,43,47,55,67,72,83}$ The information gathered related to barriers was considered to create technologies aimed at reducing barriers to care. Finally, participants' existing communication with caregivers was also assessed in three studies. ${ }^{13,69,75}$ This feedback helped create an understanding of the communication landscape of patients with others related to their disease management or healthy behaviors.

PARTICIPANT EXPERIENCES WITH TECHNOLOGIES. One study delved into participants' experiences and usage of mobile and computer technology, and how they have used different health technologies since their diagnosis. ${ }^{42}$ Others asked basic questions related to current electronic device use. ${ }^{13,43,69}$

Feedback theme 2: technological requirements. A majority of the studies received feedback about end-users' technological requirements. Feedback included (1) customization, (2) suggestions for content, (3) design and organization, (4) literacy, (5) support for using the technology, (6) security concerns, and (7) barriers to use. 


\section{MITCHELL ET AL.}

The ability to tailor and customize the health technology to the individual was the top noted technological request of the participants, and was mentioned as a requirement across all assessed studies. Customization included the following things: editable blood glucose ranges, ${ }^{13}$ tailored reminder and management systems, ${ }^{21,57,62}$ access to personal health summary data, ${ }^{59}$ and ability to set personal goals. ${ }^{51}$ Findings also pointed to a need for several customized features to support self-monitoring and management, ${ }^{21,62,67,74}$ including medication reminders and prescription renewals. ${ }^{37,50}$ Participant suggestions for content, design, and organization were a focus of nine studies, and included large buttons and letters, ${ }^{80}$ types and quality of content, ${ }^{53,86}$ ability to share data, ${ }^{51}$ graphics, ${ }^{66}$ design preferences, ${ }^{36,76}$ and simplification of features. ${ }^{62}$ In one study, children drew pictures of what features they wanted included in an interactive computer-based communication tool..$^{54}$

Four studies noted that including participant feedback in design allowed for the creation of tools to positively impact the health experiences of the users. This was encompassed as the subtheme: support for using the technology. For example, one study received positive feedback from their participants that the app prototype would help with communication and disease management. ${ }^{13}$ Participants in another study helped researchers realize that technology has the potential to address a wide range of issues, but that users must help in the determination of the most important requirements. ${ }^{64}$ In addition, one study assessed the estimated usefulness of technology and general attitudes toward technology, ${ }^{76}$ and another specifically on their interest in using the technology. ${ }^{75}$ Although interest for using the technology by patients was high in each of these cases, participants provided feedback on what would improve the technology.

Four studies mentioned barriers to technology use. Literacy was mentioned as a potential barrier, and therefore, participants recommended that development of the technologies should consider computer, information, numerical, and visual literacy. ${ }^{76,81}$ Another barrier mentioned is the violation of privacy, with some participants citing their concerns with peers finding out about their condition as a deterrent from utilization. ${ }^{38}$ Concerns over security and the potential intrusiveness of personal health information being displayed through technology were cited by participants in two of the studies. ${ }^{38,55}$ Researchers noted that these security concerns were considered when building the technology. Although the other studies did not mention security concerns, it is important to note because the development of any technology should consider security ramifications. ${ }^{87}$

Feedback theme 3: behavioral and knowledge components. Behavioral components included help with goal setting and decision making. Knowledge components included educational information on (1) a particular disease or healthy behavior, and/or (2) medication adherence.

Goal setting and help with decision making were mentioned by participants in two of the studies as particularly important to be included in the technology. ${ }^{51,70}$ For example, in one study, participants requested a calendar for planning and goal setting to track and manage their management tasks and goals. ${ }^{44}$ Knowledge components in this theme included access to information about a particular disease or healthy behavior and/or medication. These components were cited by study participants as crucial for inclusion in the health technology. Treatment information was particularly important to participants in one study, who wanted to gather robust information on treating lung cancer. ${ }^{50}$ In a second study, education through a mobile app was requested to prepare for invasive tests. $^{35}$ In another study, educational materials and trusted websites were wanted. ${ }^{37}$

Feedback theme 4: social components. Social components noted by end-users as being important included forums for peer support and creating a sense of community, communicating with the medical care team, proper message development, and advice and inspiration.

Contact with fellow patients or peers similar to the participants was noted across studies as a necessary social component to the technology. ${ }^{38,43,44,49,50,82}$ Participants wanted the ability to discuss their health and participate in social support among their peers. In addition, participants wanted to be held accountable in a way that was nonjudgmental and not overly time consuming. ${ }^{62}$ Communicating with the medical care team and other caregivers is often highly important to patients. This review found that it was important to include communication with doctors, medical staff, and other caregivers in the technology. ${ }^{13,35,50,82}$ Participants did note, however, that this communication platform should be streamlined and easy to access. Message development was also mentioned and included the types of messages appropriate for the system to deliver to the users. ${ }^{41}$ In addition, customization of messages to be sent to certain individuals at the appropriate time was noted by participants as being important, so that messages were most effective.

Participants were also interested in receiving advice regarding their chronic disease from others who also have the disease and from experts. For example, participants in one study wanted expert recommendations included in a mobile app that provided information on sun exposure and recommendations for sun protection factor in sunscreen. ${ }^{86}$ Another study had participants request advice and inspiration for eating vegetables. ${ }^{62}$ 


\section{PATIENT-CENTERED ICTS}

\section{THEORETICAL FOUNDATIONS}

Thirteen articles assessed in this review used a theory directly in the design phase and to drive the focus of development. Of the theories used, nine were social or behavioral theories, including theories such as the health belief model, ${ }^{88}$ self-determination theory, ${ }^{89}$ and the transtheoretical model of behavior change, ${ }^{90}$ and six were technological design or development frameworks, including frameworks such as the holistic framework for e-health technologies ${ }^{91}$ and the Center for eHealth Research and Disease Management or CeHReS roadmap. ${ }^{92}$ See Supplementary Appendix E for the full list of theories and a description of how the theory was used.

\section{Discussion}

Involving end-users throughout design and development better ensures the development of an effective technology. ${ }^{19}$ Usability and satisfaction feedback from patients are critical in evaluating and revising existing technologies ${ }^{93}$; however, it is important that this feedback is not the first round of information gathered from users. Going beyond usability and satisfaction, researchers and developers should explore the wants and needs of their target group through iterative, patient-centered feedback. Research has shown that to achieve optimal usability and acceptance of the ICT, the patient perspective must be considered. ${ }^{17}$ In addition, evidence has shown that patient-centered health care improves health outcomes, and therefore, there is potential for patient-centered ICTs to have similar impacts. ${ }^{25}$

Utilizing a group that is representative of all users for a particular technology is ideal to generalize the technology's effectiveness. The majority of the studies assessed in this review used a small sample of patients. This is not unexpected, as formative research methods are often time consuming and expensive. ${ }^{94,95}$ However, it is important that researchers and developers have an inclusive sample of perspectives, which may mean larger feedback groups or more iterations of feedback. In addition, researchers conducting and reporting patient-centered studies should consider including specific descriptions of their participants. As it was demonstrated in this review, many studies have not included detailed participant demographics. This information can help other researchers replicate and build from previous work and therefore, should be included in future studies.

While adherence may be difficult to maintain, reminders and treatment support can positively enforce proper management. Previous research supports the findings from this review, in that reminders have been shown to improve shortterm adherence to medication and treatment and are deemed important to patients. ${ }^{96,97}$ With the rapid development of new technology, long-term improvements in adherence may be achieved by combining time-based reminders and contentbased reminders. ${ }^{98}$ Understanding these issues from the patient perspective should help developers create engaging technologies that aim to improve health.

Many Americans, even those with strong literacy skills, often struggle to obtain and understand health information due to complex text. ${ }^{99}$ Increased health-related knowledge has the potential to positively impact health outcomes, including adherence. ${ }^{100,101}$ Comprehensive, clear treatment information was particularly important to participants in the studies reviewed. Therefore, developers should consider patient-centered feedback to understand what education their target population needs to improve knowledge and how best to present that information through the ICT.

In addition, ICTs offer a way for patients to more effectively communicate with their health care team. Patient-provider communication is essential in creating patient-centered ICTs. ${ }^{25}$ Participants' existing communication with caregivers was assessed in some of the studies in this review and is an area undergoing extensive research. Previous research has indicated that multiple forms of patient-provider communication are crucial for stronger health literacy, and that patient participation typically brings positive health outcomes. ${ }^{102,103}$ Patients and caregivers alike perceive communication tools such as web portals beneficial due to the convenience and sense of reassurance they have with direct communication. ${ }^{104-106}$ However, as noted in the findings of this review, the development of ICTs should consider security ramifications particularly for communication surrounding personal, identifying medical information. ${ }^{87,107,108}$

Research has shown benefits in health outcomes for people who have participated in support groups or other forms of peer support. ${ }^{109}$ Peer support enforces positive behavior due to their unique sense of community, information, and acceptance. ${ }^{110}$ Effective communication with a support system can positively influence a patient's healthy behaviors as it promotes medication adherence and improves comprehension of medical care information. ${ }^{11-114}$ There are several methods of support used to enhance self-management such as goal setting and help with decision making. ${ }^{115}$ Goal setting and help with decision making were noted as important components for users in many of the assessed studies. Research has shown the benefits of setting small, attainable health goals and having support in this endeavor. ${ }^{116}$

Many of the studies indicated that participants requested technologies to be tailored and customized to fit the needs of individual users. Past research in this area has shown that patients pay more attention to information that is personally relevant to them, and that it is more useful in aiding self- 


\section{MITCHELL ET AL.}

management than nontailored information. ${ }^{117}$ Customization can be achieved by displaying the patients' own information and accompanying it with suitable methods of care based on their specific needs. Using patient-centered design can help developers understand what customization is important.

This review assessed studies that used theory to drive ICT design and development. Using theoretical underpinnings to develop interventions better ensures that evaluation of the technologies may offer explanations, rather than simply predictions for if the intervention was effective. ${ }^{26}$ This review found that theory is considered for some design and development of ICTs, but not many. Future work should evaluate if use of theory impacted study results, and if there is a relationship between incorporating theory and patient-centered design on health outcomes in use of ICTs. ${ }^{118}$

As with any systematic review, this review has some limitations. First, it is possible that relevant research articles were missed as a result of the specific search criteria. In addition, many studies did not report participant demographics and therefore, reports of demographics in this review are not inclusive of all assessed studies. Future work should include descriptive participant demographic information. Not conducting a meta-analysis may be a limitation of this work; however, it is important to reiterate that the purpose of this review was to understand the current landscape of patientcentered design and development of ICTs to provide suggestions for the future development of ICTs. Future work should evaluate the outcomes of health ICT studies with and without patient-centered design to assess if impacts vary between the studies.

\section{Conclusion}

Chronic disease management and healthy behaviors are necessary for promoting positive health outcomes. ICTs can play an interesting role in aiding disease management and healthy behavior promotion, but involving end-users in the design and development of these technologies should be a consideration. The results of this systematic review indicate that participant experience, technology requirements, behavioral and knowledge components, and social components are important considerations from the perspective of patients, and should be considered in the design and development of future ICTs. In addition, using a theoretical foundation for design and development may impact the evaluation and predictability of outcomes for these technologies.

\section{Authors' Contributions}

K.M.M conceptualized and designed the study, conducted the systematic literature search, coordinated study selection, performed quality assessment, drafted the initial article, reviewed and revised the article. B.E.H aided in conceptualization and design of the study, aided in the systematic literature search, aided in article coding, and critically reviewed and edited the article. A.M. aided in article coding, and critically reviewed the article. All authors approved the final article as submitted.

\section{Disclosure Statement}

No competing financial interests exist.

\section{Supplementary Material}

Supplementary Appendix A

Supplementary Appendix B.I

Supplementary Appendix B.II

Supplementary Appendix B.III

Supplementary Appendix C

Supplementary Appendix D

Supplementary Appendix E

\section{REFERENCES}

1. National Survey of Children's Health. Data query from the Child and Adolescent Health Measurement Initiative, Data Resource Center for Child and Adolescent Health. 2012. Available at www.childhealthdata.org (last accessed August 14, 2018).

2. Torpy JM, Campbell A, Glass RM. Chronic diseases of children. JAMA 2010; 303:682.

3. Schwarzer R. Modeling health behavior change: How to predict and modify the adoption and maintenance of health behaviors. App/ Psychol 2008;57: $1-29$.

4. Haynes RB, McDonald HP, Garg AX. Helping patients follow prescribed treatment: Clinical applications. JAMA 2002;288:2880-2883.

5. Osterberg L, Blaschke T. Adherence to medication. N Engl J Med 2005;353: 487-497.

6. Bandura A. Health promotion by social cognitive means. Health Educ Behav 2004;31:143-164.

7. Rimal RN. Closing the knowledge-behavior gap in health promotion: The mediating role of self-efficacy. Health Commun 2000;12:219-237.

8. Thompson, Cullen $\mathrm{K}$, Redondo $\mathrm{M}$, Anderson B. Use of relational agents to improve family communication in type 1 diabetes: Methods. JMIR 2016; $5: e 151$.

9. Zanchi $C$, Presser AL, Vahey $P$, eds. Next generation preschool math demo: Tablet games for preschool classrooms. Proceedings of the 12th International Conference on Interaction Design and Children. New York, NY: ACM, 2013

10. Free $C$, Phillips $G$, Watson $L$, Galli L, Felix L, Edwards $P$, et al. The effectiveness of mobile-health technologies to improve health care service delivery processes: A systematic review and meta-analysis. PLoS Med 2013;10: e1001363.

11. Center PR. Who owns cellphones and smartphones 2018. Available at www.pewinternet.org/fact-sheet/mobile (last accessed August 14, 2018).

12. Heusser P. Towards Integration of 'Personalised' and 'Person-Centred' Medicine: The Concept of 'Integrative and Personalised Health Care'. Surrey, United Kingdom: Ashgate Publishing Ltd, 2015. 


\section{PATIENT-CENTERED ICTs}

13. Holtz BE, Murray KM, Hershey DD, Dunneback JK, Cotten SR, Holmstrom AJ, et al. Developing a patient-centered mHealth app: A tool for adolescents with type 1 diabetes and their parents. JMIR Mhealth Uhealth 2017;54:e53.

14. Nolte E, McKee M. Caring for People with Chronic Conditions: A Health System Perspective. Berkshire, England: McGraw-Hill Education, 2008.

15. Holtz B, Lauckner $C$. Diabetes management via mobile phones: A systematic review. Telemed J E Health 2012;18:175-184.

16. Holtz B, Murray K, Park T. Serious games for children with chronic diseases: A systematic review. Games Health J 2018;7:1-11.

17. Alpert JM, Krist AH, Aycock RA, Kreps GL. Designing user-centric patient portals: Clinician and patients' uses and gratifications. Telemed J E Health 2017;23:248-253.

18. Greenhalgh T, Hinder $S$, Stramer K, Bratan T, Russell J. Adoption, nonadoption, and abandonment of a personal electronic health record: Case study of HealthSpace. BMJ 2010;341:c5814.

19. Samaras GM, Horst RL. A systems engineering perspective on the humancentered design of health information systems. J Biomed Inform 2005;38: $61-74$.

20. Wolpin S, Stewart M. A deliberate and rigorous approach to development of patient-centered technologies. Semin Oncol Nurs 2011;27:183-191.

21. Dabbs ADV, Myers BA, Mc Curry KR, Dunbar-Jacob J, Hawkins RP, Begey A, et al. User-centered design and interactive health technologies for patients. Comput Inform Nurs 2009;27:175

22. Buntin MB, Burke MF, Hoaglin MC, Blumenthal D. The benefits of health information technology: A review of the recent literature shows predominantly positive results. Health Aff 2011;30:464-471.

23. Yen P-Y, Bakken S. Review of health information technology usability study methodologies. J Am Med Inform Assoc 2011;19:413-422.

24. Wakefield BJ, Turvey CL, Nazi KM, Holman JE, Hogan TP, Shimada SL, et al. Psychometric properties of patient-facing eHealth evaluation measures: Systematic review and analysis. J Med Internet Res 2017;19:e346.

25. Epstein RM, Fiscella $\mathrm{K}$, Lesser CS, Stange KC. Why the nation needs a policy push on patient-centered health care. Health Aff 2010;29:1489-1495.

26. Glanz K, Bishop DB. The role of behavioral science theory in development and implementation of public health interventions. Annu Rev Public Health 2010; 31:399-418.

27. Thomas J, Harden A. Methods for the thematic synthesis of qualitative research in systematic reviews. BMC Med Res Methodol 2008;8:45.

28. What is a health technology?: World Health Organization. 2018. Available at www.who.int/health-technology-assessment/about/healthtechnology/en/ (last accessed August 14, 2018).

29. Åkesson KM, Saveman B-I, Nilsson G. Health care consumers' experiences of information communication technology-A summary of literature. Int J Med Inform 2007;76:633-645.

30. Bechtel C, Ness DL. If you build it, will they come? Designing truly patientcentered health care. Health Aff 2010;29:914-920.

31. Garrett JJ. The Elements of User Experience: User-Centered Design for the Web and Beyond. Berkeley, CA: Pearson Education, 2010.

32. Krippendorff K. Computing Krippendorff's alpha-reliability. 2011.

33. Liumbruno GM, Velati $C$, Pasqualetti $P$, Franchini M. How to write a scientific manuscript for publication. Blood Transfus 2013;11:217.

34. Boyd AD, Moores K, Shah V, Sadhu E, Shroff A, Groo V, et al. My interventional drug-eluting stent educational app (MyIDEA): Patient-centered design methodology. JMIR Mhealth Uhealth 2015;3:e74.

35. Buzzacchino S, Lanzola G, Bossi P, Licitra L, Quaglini S. A mobile application supporting outpatient treatment and follow-up. Stud Health Technol Inform 2015;210:788-792.

36. Fernon A, Nguyen A, Baysari M, Day R. A user-centred approach to designing an etool for gout management. Stud Health Technol Inform 2016;227:28-33.
37. Gray CS, Khan Al, Kuluski K, McKillop I, Sharpe S, Bierman AS, et al. Improving patient experience and primary care quality for patients with complex chronic disease using the electronic patient-reported outcomes tool: Adopting qualitative methods into a user-centered design approach. JMIR Res Protoc 2016;5:e28.

38. Groussard P-Y, Pigot $H$, Giroux S. From conception to evaluation of mobile services for people with head injury: A participatory design perspective. Neuropsychol Rehabil 2018;28:667-688.

39. Huberty J, Rowedder L, Hekler E, Adams M, Hanigan E, McClain D, et al. Development and design of an intervention to improve physical activity in pregnant women using Text4baby. Trans/ Behav Med 2015;6:285-294.

40. Nazneen N, Rozga A, Smith CJ, Oberleitner R, Abowd GD, Arriaga RI. A novel system for supporting autism diagnosis using home videos: Iterative development and evaluation of system design. JMIR Mhealth Uhealth 2015; 3:e68.

41. Owens $C$, Farrand $P$, Darvill $R$, Emmens $T$, Hewis $E_{1}$ Aitken $P$. Involving service users in intervention design: A participatory approach to developing a textmessaging intervention to reduce repetition of self-harm. Health Expect $2011 ; 14: 285-295$

42. Pulman A, Hill J, Taylor J, Galvin K, Masding MG. Innovative mobile technology alcohol education for young people with type 1 diabetes. Pract Diabetes 2013;30:376

43. Raval MV, Taylor N, Piper K, Thakore M, Hoff K, Owens S, et al. Pediatric patient and caregiver preferences in the development of a mobile health application for management of surgical colorectal conditions. J Med Syst 2017;41:105.

44. Revenäs $\AA$, Opava CH, Martin C, Demmelmaier I, Keller C, Åsenlöf P. Development of a web-based and mobile app to support physical activity in individuals with rheumatoid arthritis: Results from the second step of a codesign process. JMIR Res Protoc 2015;4:e22.

45. Rothgangel A, Braun S, Smeets R, Beurskens A. Design and development of a telerehabilitation platform for patients with phantom limb pain: A usercentered approach. JMIR Rehabil Assist Technol 2017;4:e2.

46. Schnall R, Rojas M, Travers J, Brown III W, Bakken S, eds. Use of design science for informing the development of a mobile app for persons living with HIV. AMIA Annual Symposium Proceedings. Washington, DC: American Medical Informatics Association, 2014.

47. Skjøth MM, Hansen HP, Draborg E, Pedersen CD, Lamont RF, Jørgensen JS. Informed choice for participation in Down syndrome screening: Development and content of a web-based decision aid. JMIR Res Protoc 2015;4:e113.

48. Taylor DP, Bray BE, Staggers N, Olson RJ, eds. User-centered development of a Web-based preschool vision screening tool. AMIA Annual Symposium Proceedings. Washington, DC: American Medical Informatics Association, 2003.

49. Terp $M$, Laursen BS, Jørgensen $R$, Mainz J, Bjørnes CD. A room for design: Through participatory design young adults with schizophrenia become strong collaborators. Int J Ment Health Nurs 2016;25:496-506.

50. Timmerman JG, Tönis TM, Dekker-van Weering MG, Stuiver MM, Wouters MW, van Harten WH, et al. Co-creation of an ICT-supported cancer rehabilitation application for resected lung cancer survivors: Design and evaluation. BMC Health Serv Res 2016;16:155.

51. van der Weegen $S$, Verwey $R$, Spreeuwenberg $M$, Tange $H$, van der Weijden $T$, de Witte L. The development of a mobile monitoring and feedback tool to stimulate physical activity of people with a chronic disease in primary care: A user-centered design. JMIR Mhealth Uhealth 2013;1:e8.

52. Neubeck L, Coorey G, Peiris D, Mulley J, Heeley E, Hersch F, et al. Development of an integrated e-health tool for people with, or at high risk of, cardiovascular disease: The Consumer Navigation of Electronic Cardiovascular Tools (CONNECT) web application. Int J Med Inform 2016;96:24-37.

53. Winterling J WM, Obol CM, Lampic C, Eriksson LE, Pelters B, Wettergren L Development of a self-help web-based intervention targeting young cancer patients with sexual problems and fertility distress in collaboration with patient research partners. JMIR Res Protoc 2016;5:e60. 


\section{MITCHELL ET AL.}

54. Arvidsson S, Gilljam B-M, Nygren J, Ruland CM, Nordby-Bøe T, Svedberg P. Redesign and validation of Sisom, an interactive assessment and communication tool for children with cancer. JMIR Mhealth Uhealth 2016;4:e76.

55. Fonda SJ, Kedziora RJ, Vigersky RA, Bursell S-E. Combining i Google and personal health records to create a prototype personal health application for diabetes self-management. Telemed J E Health 2010;16:480-489.

56. Fonda SJ, Kedziora RJ, Vigersky RA, Bursell S-E. Evolution of a web-based, prototype Personal Health Application for diabetes self-management. J Biomed Inform 2010;43:S17-S21.

57. Garnweidner-Holme LM, Borgen I, Garitano I, Noll J, Lukasse M. Designing and developing a mobile smartphone application for women with gestational diabetes mellitus followed-up at diabetes outpatient clinics in Norway. Healthcare (Basel) 2015;3:310-323.

58. Herschman J, Kasenberg T, Levy D, Ruth N, Taberner C, Kaufman M, et al. Development of a smartphone app for adolescents with lupus: A collaborative meeting-based methodology inclusive of a wide range of stakeholders. Rev Panam Salud Publica 2014;35:471-476.

59. Hogarth M, Hajopoulos K, Young M, Cowles N, Churin J, Hornthal B, et al. The communication and care plan: A novel approach to patient-centered clinical information systems. J Biomed Inform 2010;43:S6-S8.

60. Huguet A, Stinson J, Mackay B, Watters $C$, Tougas $M$, White $M$, et al. Bringing psychosocial support to headache sufferers using information and communication technology: Lessons learned from asking potential users what they want. Pain Res Manag 2014;19:e1-e8.

61. Maas $A H$, van der Molen $P$, van de Vijver $R$, Chen W, van Pul C, Cottaar EJ, et al. Concept development of the Eindhoven diabetes education simulator project. Games Health J 2016;5:120-127.

62. Mummah $S A$, King $A C$, Gardner $C D$, Sutton $S$. Iterative development of Vegethon: $A$ theory-based mobile app intervention to increase vegetable consumption. Int J Behav Nutr Phys Act 2016;13:90.

63. Peters D, Davis S, Calvo RA, Sawyer SM, Smith L, Foster JM. Young people's preferences for an asthma self-management app highlight psychological needs: A participatory study. J Med Internet Res 2017;19:e113.

64. Robinson L, Brittain K, Lindsay S, Jackson D, Olivier P. Keeping In Touch Everyday (KITE) project: Developing assistive technologies with people with dementia and their carers to promote independence. Int Psychogeriatr 2009; 21:494-502.

65. Sanger $\mathrm{PC}$, Hartzler $\mathrm{A}$, Lordon RJ, Armstrong $\mathrm{CA}$, Lober WB, Evans $\mathrm{HL}$, et al. A patient-centered system in a provider-centered world: Challenges of incorporating post-discharge wound data into practice. J Am Med Inform Assoc 2016;23:514-525.

66. Sockolow P, Schug S, Zhu J, Smith T, Senathirajah Y, Bloom S. At-risk adolescents as experts in a new requirements elicitation procedure for the development of a smart phone psychoeducational trauma-informed care application. Inform Health Soc Care 2017;42:77-96.

67. Stinson JN, Lalloo C, Harris L, Isaac L, Campbell F, Brown S, et al. iCanCope with Pain ${ }^{\mathrm{TM}}$ : User-centred design of a web-and mobile-based selfmanagement program for youth with chronic pain based on identified health care needs. Pain Res Manag 2014;19:257-265.

68. Ashurst EJ, Jones RB, Abraham C, Jenner M, Boddy K, Besser RE, et al. The diabetes app challenge: User-led development and piloting of internet applications enabling young people with diabetes to set the focus for their diabetes consultations. Med 20 2014;3:e5.

69. Banas JR, Victorson D, Gutierrez S, Cordero E, Guitleman J, Haas N. Developing a peer-to-peer mHealth application to connect Hispanic cancer patients. J Cancer Educ 2017;32:158-165.

70. Cafazzo JA, Casselman M, Hamming N, Katzman DK, Palmert MR. Design of an mHealth app for the self-management of adolescent type 1 diabetes: $\mathrm{A}$ pilot study. J Med Internet Res 2012;14:e70.

71. Connelly K, Stein KF, Chaudry B, Trabold N. Development of an ecological momentary assessment mobile app for a low-literacy, mexican american population to collect disordered eating behaviors. JMIR Public Health Surveill 2016;2:e31.

72. Curtis KE, Lahiri S, Brown KE. Targeting parents for childhood weight management: Development of a theory-driven and user-centered healthy eating app. JMIR Mhealth Uhealth 2015;3:e69.

73. Duh ES, Guna J, Pogačnik $M$, Sodnik J. Applications of paper and interactive prototypes in designing telecare services for older adults. J Med Syst 2016; 40:92.

74. Haque MM, Kawsar F, Adibuzzaman M, Uddin MM, Ahamed SI, Love R, et al. e-ESAS: Evolution of a participatory design-based solution for breast cancer (BC) patients in rural Bangladesh. Pers Ubiquitous Comput 2015;19:395-413.

75. Lyles $C R$, Altschuler $A$, Chawla N, Kowalski C, McQuillan D, Bayliss E, et al. User-centered design of a tablet waiting room tool for complex patients to prioritize discussion topics for primary care visits. JMIR Mhealth Uhealth 2016;4:e108.

76. Muuraiskangas $S$, Leist AK, Braun A, Klauß K, Roelofsma PH, Wichert $R$, et al. V2me: Evaluating the first steps in mobile friendship coaching. J Ambient Intell Smart Environ 2012;4:517-534.

77. Narváez S, Tobar ÁM, López DM, Blobel B. Human-centered design of an mHealth app for the prevention of burnout syndrome. Stud Health Technol Inform 2016;228:215-219.

78. Storni C. Diabetes self-care in-the-wild: Design challenges for personal health record systems and self-monitoring technologies. Inf Technol People 2014; 27:397-420.

79. Trujillo A, Buzzi MC, eds. Participatory user requirements elicitation for personal menopause app. Proceedings of the 9th Nordic Conference on Human-Computer Interaction. Gothenburg, Sweden: ACM, 2016.

80. Vermeulen J, Neyens JC, Spreeuwenberg MD, van Rossum E, Sipers W, Habets

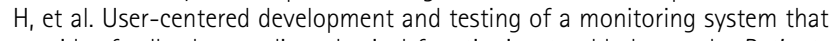
provides feedback regarding physical functioning to elderly people. Patient Prefer Adherence 2013;7:843.

81. Welch JL, Siek KA, Connelly KH, Astroth KS, McManus MS, Scott L, et al. Merging health literacy with computer technology: Self-managing diet and fluid intake among adult hemodialysis patients. Patient Educ Couns 2010;79:192-198.

82. Gibson F, Aldiss S, Taylor RM, Maguire R, McCann L, Sage M, et al. Utilization of the medical research council evaluation framework in the development of technology for symptom management: The ASyMS@-YG study. Cancer Nurs 2010;33:343-352.

83. Giesbrecht EM, Miller WC, Mitchell IM, Woodgate RL. Development of a wheelchair skills home program for older adults using a participatory action design approach. Biomed Res Int 2014;2014:172434.

84. Gordon $\mathrm{M}$, Henderson $\mathrm{R}$, Holmes JH, Wolters MK, Bennett IM, Group S. Participatory design of ehealth solutions for women from vulnerable populations with perinatal depression. J Am Med Inform Assoc 2015;23:105-109.

85. da Silva CC, da Silva Filho AG, Monteiro JS, dos Santos WP, eds. Developing $3 \mathrm{D}$ human-computer interfaces and serious games for health education in the Brazilian countryside using participatory design and popular education. 2014 IEEE International Conference on Systems, Man and Cybernetics (SMC). San Diego, CA: IEEE, 2014.

86. Buller DB, Berwick M, Shane J, Kane I, Lantz K, Buller MK. User-centered development of a smart phone mobile application delivering personalized real-time advice on sun protection. Transl Behav Med 2013;3:326-334.

87. Weber RH. Internet of Things-New security and privacy challenges. Comput Law Secur Rev 2010;26:23-30.

88. Rosenstock IM. Historical origins of the health belief model. Health Educ Monogr 1974;2:328-335.

89. Deci EL, Ryan RM. Self-determination theory. Handb Theor Soc Psychol 2011; 1:416-433.

90. Prochaska JO, Velicer WF. The transtheoretical model of health behavior change. Am J Health Promot 1997;12:38-48. 


\section{PATIENT-CENTERED ICTs}

91. van Gemert-Pijnen JE, Nijland N, van Limburg M, Ossebaard HC, Kelders SM, Eysenbach $\mathrm{G}$, et al. A holistic framework to improve the uptake and impact of eHealth technologies. J Med Internet Res 2011;13:e111.

92. Van Gemert-Pijnen J. The CeHRes roadmap. In: Van Gemert-Pijnen JEWC, Peters 0, Ossebaard HC, eds. Improving eHealth. The Hague, The Netherlands: ISBN: Eleven International Publishing, 978-94-6236-067. 2013;9:33-48.

93. Battleson $B$, Booth $A$, Weintrop J. Usability testing of an academic library web site: A case study. J Acad Libr 2001;27:188-198.

94. Guba EG, Lincoln YS. Effective Evaluation: Improving the Usefulness of Evaluation Results Through Responsive and Naturalistic Approaches. San Francisco, CA: Jossey-Bass, 1981

95. Patton MO. Qualitative Evaluation and Research Methods. SAGE Publications Inc., 1990.

96. Pop-Eleches $C$, Thirumurthy $H$, Habyarimana JP, Zivin JG, Goldstein MP, De Walque $D$, et al. Mobile phone technologies improve adherence to antiretroviral treatment in a resource-limited setting: A randomized controlled trial of text message reminders. AIDS $2011 ; 25: 825$.

97. Vervloet $M$, van Dijk $L$, Santen-Reestman J, Van Vlijmen $B$, Van Wingerden $P$, Bouvy ML, et al. SMS reminders improve adherence to oral medication in type 2 diabetes patients who are real time electronically monitored. Int J Med Inform 2012;81:594-604

98. Vervloet $M$, Linn AJ, van Weert JC, De Bakker DH, Bouvy ML, Van Dijk L. The effectiveness of interventions using electronic reminders to improve adherence to chronic medication: A systematic review of the literature. J Am Med Inform Assoc 2012;19:696-704.

99. Kindig DA, Panzer AM, Nielsen-Bohlman L. Health Literacy: A Prescription to End Confusion. Washington, DC: National Academies Press, 2004.

100. Gazmararian JA, Williams MV, Peel J, Baker DW. Health literacy and knowledge of chronic disease. Patient Educ Couns 2003;51:267-275.

101. Lorig KR, Sobel DS, Stewart AL, Brown BW Jr., Bandura A, Ritter $P$, et al. Evidence suggesting that a chronic disease self-management program can improve health status while reducing hospitalization: A randomized trial. Med Care 1999;37:5-14

102. Nouri SS, Rudd RE. Health literacy in the "oral exchange": An important element of patient-provider communication. Patient Educ Couns 2015;98: 565-571.

103. Stevenson FA, Cox K, Britten N, Dundar Y. A systematic review of the research on communication between patients and health care professionals about medicines: The consequences for concordance. Health Expect 2004; $7: 235-245$

104. Volk LA, Pizziferri L, Wald J, Bates DW, eds. Patients' perceptions of a web portal offering clinic messaging and personal health information. AMIA Annual Symposium Proceedings. Washington, DC: American Medical Informatics Association, 2005.

105. Britto MT, Hesse EA, Kamdar OJ, Munafo JK. Parents' perceptions of a patient portal for managing their child's chronic illness. J Pediatr 2013;163:280281.e2.

106. Lin C-T, Wittevrongel L, Moore L, Beaty BL, Ross SE. An Internet-based patient-provider communication system: Randomized controlled trial. J Med Internet Res 2005;7:e47.
107. Olanrewaju R, Ali Na, Khalifa O, Manaf AA. ICT in Telemedicine: Conquering privacy and security issues in health care services. Electron J Comput Sci Inf Technol 2013;4:19-24.

108. Ruivo P, Santos $V$, Oliveira T. Data protection in services and support rolesa qualitative research amongst ICT professionals. Proc Technol 2014;16: 710-717.

109. Solomon P. Peer support/peer provided services underlying processes, benefits, and critical ingredients. Psychiatr Rehabil J 2004;27:392.

110. Ussher J, Kirsten L, Butow P, Sandoval M. What do cancer support groups provide which other supportive relationships do not? The experience of peer support groups for people with cancer. Soc Sci Med 2006;62:2565-2576.

111. Ye J, Rust G, Fry-Johnson Y, Strothers H. E-mail in patient-provider communication: A systematic review. Patient Educ Couns 2010;80: 266-273.

112. Stewart MA. Effective physician-patient communication and health outcomes: A review. CMAJ 1995;152:1423.

113. Zandbelt LC, Smets EM, Oort FJ, Godfried MH, de Haes HC. Patient participation in the medical specialist encounter: Does physicians' patientcentred communication matter? Patient Educ Couns 2007;65:396-406.

114. Rothman AJ, Salovey $P$, Antone $C$, Keough $K$, Martin CD. The influence of message framing on intentions to perform health behaviors. J Exp Soc Psychol 1993;29:408-433.

115. Lawn S, Schoo A. Supporting self-management of chronic health conditions: Common approaches. Patient Educ Couns 2010;80:205-211.

116. Strecher VJ, Seijts GH, Kok GJ, Latham GP, Glasgow R, DeVellis B, et al. Goal setting as a strategy for health behavior change. Health Educ 0 1995;22: 190-200.

117. Kreuter MW, Farrell DW, Olevitch LR, Brennan LK. Tailoring Health Messages: Customizing Communication with Computer Technology. New York, NY: Routledge, 2013.

118. Hekler EB, Michie S, Pavel M, Rivera DE, Collins LM, Jimison HB, et al. Advancing models and theories for digital behavior change interventions. Am J Prev Med 2016;51:825-832.

Address correspondence to: Katharine M. Mitchell, MA Department of Advertising \& Public Relations Michigan State University 404 Wilson Road, Rm 309 East Lansing, MI 48824-1212

E-mail: murra172@msu.edu

Received: September 12, 2018

Revised: October 17, 2018

Accepted: October 24, 2018

Online Publication Date: December 21, 2018 